\title{
Erythrocyte deformability in peripheral occlusive arterial disease
}

\author{
D BAREFORD, GS LUCAS, NM CALDWELL, PCW STONE, S BAAR, J STUART \\ From the Department of Haematology, The Medical School, University of Birmingham, Birmingham \\ B15 2TJ
}

SUMMARY A rheological study of 32 patients with peripheral occlusive arterial disease (POAD), compared with 32 matched healthy controls, has shown no loss of erythrocyte deformability as measured by filtration methods (using initial flow rate and positive pressure instruments, polycarbonate and silver membranes, and $3 \mu \mathrm{m}$ and $5 \mu \mathrm{m}$ diameter pores) or by viscometry (using laser visco-diffractometric and high shear rate viscosity methods). Erythrocyte ATP concentration in POAD was also normal. Patients with POAD showed a small (4 f) increase in mean erythrocyte volume, associated with a raised serum $\gamma$-glutamyl transpeptidase concentration, which correlated with erythrocyte filtration and viscometric measurements. Previous reports of impaired blood filterability in POAD probably reflect the effects of accompanying leucocytosis, plasma hyperfibrinogenaemia, or an increase in erythrocyte size, but not an intrinsic loss of erythrocyte deformability.

Patients with atherosclerotic peripheral occlusive arterial disease (POAD) show an increase in whole blood viscosity which is of prognostic significance and is, at least in part, caused by a raised plasma fibrinogen concentration. ${ }^{2}$ Whole blood viscosity is also influenced by erythrocyte deformability, however, and a reduction in the deformability (filterability) of POAD erythrocytes has been reported in several studies. Blood filtration through pores of $5 \mu \mathrm{m}$ diameter is, however, influenced by factors extrinsic to the erythrocyte, such as the plasma fibrinogen concentration ${ }^{3}$ and the number of contaminating leucocytes. ${ }^{45}$ Since POAD patients may show hyperfibrinogenaemia or a leucocytosis as part of the haematological stress syndrome, ${ }^{67}$ previous reports of either reduced whole blood filtration, ${ }^{8-11}$ reduced filtration of erythrocytes suspended in autologous plasma, ${ }^{12}{ }^{13}$ and reduced filtration of washed erythrocytes contaminated with leucocytes, ${ }^{14}$ may reflect these extra-erythrocytic factors. This is supported by the failure to show any persisting loss of erythrocyte filterability when POAD erythrocytes are suspended in normal plasma ${ }^{15}$ or when erythrocyte filtration is corrected mathematically for contaminating leucocytes using regression lines. ${ }^{416}$

Accepted for publication 29 October 1984
Although erythrocyte filtration is sensitive to leucocyte contamination, ${ }^{5}$ regression line correction methods ${ }^{46}$ may introduce other errors and reduce test sensitivity to alterations in erythrocyte deformability. There has been no previous report of the filterability of leucocyte free, washed POAD erythrocytes, and we have therefore studied the erythrocyte deformability of 32 POAD patients and 32 matched controls using initial flow rate (Hemorheometre) and positive pressure (Erythrometre) filtration methods. Viscometric measurements of erythrocyte deformability were also made using Contraves LS30 and laser diffractometric (Ektacytometer) instruments. Since a reduced erythrocyte ATP concentration has been reported in POAD, ${ }^{17}$ and has been claimed to be a cause of decreased erythrocyte deformability, we have also studied erythrocyte ATP in a cohort of patients and healthy controls.

\section{Patients and methods}

\section{PATIENTS}

The 32 patients with POAD (age range 50-77 years, 25 male) were studied as outpatients or on admission for angiography. All had atherosclerotic, nondiabetic, large vessel disease, confirmed by angiography and by reduced or absent peripheral pulses. All were normotensive and there was no biochemi- 
Table 1 Comparison of mean (SEM) haematological and biochemical values for 32 patients with peripheral occlusive arterial disease (POAD) and 32 matched controls

\begin{tabular}{|c|c|c|c|}
\hline & $P O A D$ & Significance $p$ & Controls \\
\hline $\begin{array}{l}\text { Age }(\mathrm{yr}) \\
\text { Smokers } \\
\text { Leucocyte count }\left(\times 10^{\varphi} / \mathrm{l}\right) \\
\text { Erythrocyte mean cell volume }(\mathrm{fl}) \\
\gamma \text {-glutamyl transpeptidase }(\mathrm{U} / \mathrm{ml}) \\
\text { Plasma viscosity (mPas) } \\
{ }^{*} \text { Erythrocyte ATP }(\mu \mathrm{mol} / \mathrm{l})\end{array}$ & $\begin{array}{c}63 \cdot 3(1 \cdot 1) \\
16 \\
7 \cdot 8(0 \cdot 4) \\
92 \cdot 8(0 \cdot 8) \\
27 \cdot 5(5 \cdot 9) \\
1.80(0 \cdot 02) \\
464.9(17 \cdot 9)\end{array}$ & $\begin{array}{l}\text { NS } \\
\text { NS } \\
\quad 0.001 \\
<0.01 \\
<0.001 \\
\text { NS }\end{array}$ & $\begin{array}{c}61.6(1.7) \\
16 \\
7.9(0.4) \\
88.9(0.7) \\
13.6(2.0) \\
1.70(0.02) \\
497.5(25 \cdot 2)\end{array}$ \\
\hline
\end{tabular}

NS = not significant.

*Mann-Whitney U test for 20 patients and 21 controls.

cal evidence of renal insufficiency. Rest pain was present in three but none had gangrene; the mean (range) claudication distance was 250 (45-1500) metres. The 32 healthy controls (age range 44-77 years, 25 male) were closely matched (Table 1) for age and smoking habit and had no clinical evidence of vascular disease; biochemical tests of liver and renal function were normal. POAD smokers averaged 14 cigarettes a day and control smokers 20 a day.

\section{METHODS}

Blood samples for all rheological tests were taken from an antecubital vein into lithium heparin (15 IU/ml blood; Sterilin Ltd, Feltham, Middlesex) and analysed within $4 \mathrm{~h}^{5}$ Erythrocyte filterability was measured using erythrocytes that were leucocyte and platelet free as prepared by the Imugard IG500 cotton wool prefiltration technique followed by two washes in phosphate buffered saline (PBS) of $\mathrm{pH} 7.4$ and osmolality $297 \mathrm{mmol} / \mathrm{kg}{ }^{1819}$ More than $99.5 \%$ of leucocytes and platelets (as assessed by Neubauer counting chamber) were consistently removed. Initial flow rate filtration ${ }^{20}$ was measured at ambient temperature using the Hemorheometre SPO2 (Bell System [Telephones] Ltd, Barnet) as previously described. ${ }^{21}$ Disposable polycarbonate membranes of $5 \mu \mathrm{m}$ pore diameter, taken from a single batch (Nuclepore Corporation, Pleasanton, California, USA; batch 54 FOC 138), and reusable silver Selas membranes of nominal $5 \mu \mathrm{m}$ (batch 5872) and $3 \mu \mathrm{m}$ (batch 013) pore diameter (Flotronics, Spring House, Pennsylvania 19477, USA), were used. The silver membranes were cleaned and reused after each erythrocyte filtration as previously described ${ }^{21}$ but were ultrasonicated for a total of $10 \mathrm{~s}$ in $20 \mathrm{ml}$ of $1 \%$ $\mathrm{wt} / \mathrm{vol}$ sodium dodecyl sulphate solution. Hemorheometre results were expressed as an index of filtration (IF) after correction for haematocrit ${ }^{20}$ as measured by Coulter $S$ counter (Coulter Electronics Ltd, Luton). IF was measured only once using the silver membrane, but two measurements were made using (different) polycarbonate membranes and the mean taken. When the latter two values were not within $10 \%$ (about $1 / 5$ of all tests) a third membrane was used and the mean of the closest two readings was then taken.

Positive pressure erythrocyte filtration was measured at ambient temperature, again after passage of blood through Imugard IG500 cotton wool, using the Erythrometre II (SEFAM, Nancy, France) at a standard washed erythrocyte count (Coulter ZF counter) of $0.5 \times 10^{12} / \mathrm{l}$, a flow rate of $5 \mathrm{ml} / \mathrm{min}$, and $5 \mu \mathrm{m}$ pore diameter Nuclepore filters. Results were expressed as a filtration pressure index (I) by dividing the final pressure at $3 \mathrm{~min}$ by that for buffer alone at $1 \mathrm{~min}^{22}$ Only one measurement of I was made on each blood sample.

Laser visco-diffractometry measurements on whole blood were made at ambient temperature using the Ektacytometer (Technicon International Division, Saint Denis, France) as previously described..$^{23}{ }^{24}$ The parameters measured included the elongation index (EI) for whole blood, at a shear stress of $16 \mathrm{~Pa}$, and the osmotic deformability profile, ${ }^{25}$ or Osmoscan plot, in which erythrocyte elongation is measured in a continuously increasing osmotic gradient $(100-450 \mathrm{mmol} / \mathrm{kg})$. The maximum elongation index in the latter (EI max) was recorded.

Red cell viscosity was measured at $25^{\circ} \mathrm{C}$ using erythrocytes that were washed three times in PBS (but without contact with Imugard IG500 cotton wool), resuspended in PBS at $2.0 \times 10^{12} / 1$, and sheared at a rate of 241 per second in a Contraves LS30 2T-8T viscometer (Contraves Industrial Products Ltd, Ruislip) as previously described. ${ }^{26}$ Plasma viscosity was measured at $25^{\circ} \mathrm{C}$ using a Coulter-Harkness capillary viscometer (Coulter Electronics Ltd).

Erythrocyte ATP concentration was measured in 20 patients and 21 controls by ultraviolet spectrophotometry (Pye Unicam SP8-100, Cambridge) using a Test-Combination ATP kit (Boehringer Mannheim GmbH Diagnostica) based on the 
method of Bücher. ${ }^{27} \gamma$-glutamyl transpeptidase was assayed at $25^{\circ} \mathrm{C}$ using a Merck test kit (EM Diagnostics, Poole) and a Kone CD analyser (Kone Instruments, Stockport). Serum biochemical profile was measured by SMA 12/60 (Technicon Instruments, Basingstoke). Erythrocyte mean cell volume (MCV) was measured by a Coulter $S$ counter. Quality assurance was determined for the Hemorheometre and Erythrometre methods by daily measurements of the flow time of a sterile aliquot of dextran 70 in $0.9 \%$ sodium chloride (Fisons Ltd, Loughborough) through the $5 \mu \mathrm{m}$ pore polycarbonate and silver membranes, as previously described. ${ }^{21}$

Statistical significance was determined by the Mann-Whitney $U$ test (two tail) and by correlation coefficient.

\section{Results}

The 32 patients were closely matched for age, sex, and smoking habit, and fortuitously for leucocyte count, with the 32 healthy controls (Table 1). The patients' erythrocytes showed a significantly higher $\mathrm{MCV}$, presumed to be a consequence of higher alcohol intake since nine patients, but only two controls, had serum $\gamma$-glutamyl transpeptidase concentrations above the upper limit of the reference range $(6-25 \mathrm{U} / \mathrm{ml})$; the mean $\gamma$-glutamyl transpeptidase concentration of the patients was significantly higher than that of the controls (Table 1). The patients also showed significantly higher plasma viscosities than the controls, but the mean erythrocyte ATP concentration (reference range 375-631 $\mu \mathrm{mol} / \mathrm{l}$ ) was not significantly different.

Quality assurance was satisfactory for the $5 \mu \mathrm{m}$ filtration methods. Coefficients of variation (CV) were calculated from the daily flow times of dextran
70 for each of the 45 working days of the study. The Hemorheometre 45-day CVs were $4.8 \%$ for $5 \mu \mathrm{m}$ polycarbonate membranes and $6.6 \%$ for $5 \mu \mathrm{m}$ silver membranes. A 45-day CV of $12.0 \%$ was obtained for the Erythrometre using $5 \mu \mathrm{m}$ polycarbonate membranes.

None of the tests of erythrocyte filterability showed a significant difference between patients and controls (Table 2). The IF values for $5 \mu \mathrm{m}$ pore polycarbonate and silver membranes closely correlated with one another within both the 32 patients ( $r$ $=0.700, p<0.001)$ and the 32 controls $(r=0.618$, $p<0.001)$. Thus despite the difference between the straight channel pores of the polycarbonate membranes and the tortuous channel pores of the sintered silver membranes, the indices of filterability were similar. There was no significant correlation between the initial flow rate IF values, using $5 \mu \mathrm{m}$ pore polycarbonate membranes, and the I values obtained after positive pressure filtration for $3 \mathrm{~min}$ using similar membranes; these two filtration indices therefore seem to measure different rheological parameters.

A larger group of 99 subjects (40 POAD patients and 59 healthy controls), from which the 32 matched pairs were taken, was used to assess the relation between MCV and IF values. MCV correlated weakly but significantly with IF for both $5 \mu \mathrm{m}$ pore polycarbonate $(\mathrm{r}=0.213, \mathrm{p}<0.05)$ and $5 \mu \mathrm{m}$ pore silver $(r=0.210, p<0.05)$ membranes; MCV did not correlate significantly with $\mathrm{I}$, however $(\mathrm{r}=$ 0.091). Within the smaller number of 32 matched POAD patients, and within the 32 controls, there was no significant correlation between MCV and any of the above filtration measurements.

Measurement of red cell viscosity at high shear rate did not show any significant difference between POAD patients and controls, but laser visco-

Table 2 Comparison of mean (SEM) rheological values for 32 patients with peripheral occlusive arterial disease (POAD) and 32 matched controls

\begin{tabular}{|c|c|c|c|}
\hline & $P O A D$ & Significance $p$ & Controls \\
\hline $\begin{array}{l}\text { Initial flow rate filtration (IF) } \\
\text { Polycarbonate } 5 \mu \mathrm{m} \\
\text { Silver } 5 \mu \mathrm{m} \\
{ }^{*} \text { Silver } 3 \mu \mathrm{m}\end{array}$ & $\begin{array}{l}13.8(0.2) \\
11.7(0.2) \\
30.9(1.3)\end{array}$ & $\begin{array}{l}\text { NS } \\
\text { NS } \\
\text { NS }\end{array}$ & $\begin{array}{l}13 \cdot 5(0 \cdot 9) \\
11 \cdot 3(0 \cdot 2) \\
33 \cdot 1(2 \cdot 3)\end{array}$ \\
\hline $\begin{array}{l}\text { Positive pressure filtration (I) } \\
\text { Polycarbonate } 5 \mu \mathrm{m} \\
\text { Red cell viscosity (mPas) } \\
\text { Laser visco-diffractometry }\end{array}$ & $\begin{array}{l}2 \cdot 0(0 \cdot 1) \\
1 \cdot 66(0 \cdot 01)\end{array}$ & $\begin{array}{l}\text { NS } \\
\text { NS }\end{array}$ & $\begin{array}{l}1.9(0.1) \\
1.63(0.02)\end{array}$ \\
\hline $\begin{array}{l}\mathrm{EI} \\
\mathrm{EI} \\
\max \end{array}$ & $\begin{array}{l}0.55(0.01) \\
0.58(0.01)\end{array}$ & $\begin{array}{l}<0.02 \\
<0.05\end{array}$ & $\begin{array}{l}0.53(0.01) \\
0.57(0.01)\end{array}$ \\
\hline
\end{tabular}

*Mann-Whitney $U$ test for 13 patients and 12 controls.

IF $=$ index of filtration.

I = filtration pressure index.

$\mathrm{EI}=$ elongation index

$\mathrm{NS}=$ not significant. 
diffractometry showed apparently increased elongability (EI and $E I_{\max }$ ) for POAD erythrocytes (Table 2). This is in part an instrument artefact since EI correlated with MCV within the 32 patients ( $r=$ $0.352, \mathrm{p}<0.05)$ and within the 32 controls $(\mathrm{r}=$ $0.552, \mathrm{p}<0.01$ ); analysis of the diffraction image in the Ektacytometer is not compensated for cell size. Apart from EI, the Ektacytometer Osmoscan plots, which showed the relation between erythrocyte elongation index and osmolality, were similar between patients and controls.

\section{Discussion}

In this study particular care was taken to match POAD patients with healthy controls and to use a range of rheological methods that measure different aspects of erythrocyte deformability. Our filtration methods included an initial flow rate gravity system (Hemorheometre), with a calculated maximum shear stress of $60 \mathrm{~Pa}$, and a positive pressure filtration system (Erythrometre), with a shear stress of $37 \mathrm{~Pa}$ for normal erythrocytes. With the exception of Ehrly and Köhler, ${ }^{12}$ who used $8 \mu \mathrm{m}$ pore diameter Millipore filters, previous filtration studies in POAD have almost exclusively employed $5 \mu \mathrm{m}$ pore disposable polycarbonate (Nuclepore) membranes. In addition to these membranes we studied reusable silver membranes of both $5 \mu \mathrm{m}$ and $3 \mu \mathrm{m}$ nominal pore diameter since they may have differing sensitivity in the detection of impaired erythrocyte deformability. ${ }^{21}$ A quality assurance programme was also used throughout the study and this showed satisfactory day to day instrument and membrane reproducibility.

Our filtration measurements were performed on erythrocytes that had been passed through Imugard IG500 cotton wool and then washed twice in PBS. This technique removes $>99.5 \%$ of leucocytes and platelets, as well as plasma proteins, but does not cause selective removal of erythrocyte subpopulations such as microcytes, macrocytes, reticulocytes, irreversibly sickled cells, or erythrocytes containing inclusion bodies. ${ }^{18}$ Although we have not yet been able to show that the cotton wool does trap any erythrocyte sub-populations, it is theoretically possible that less deformable POAD erythrocytes could have been selectively removed. Additional (viscometric) methods for measuring erythrocyte deformability, without cotton wool contact, were therefore studied in parallel.

None of the rheological methods used showed any loss of deformability of POAD erythrocytes and we assume that previous studies showing loss of erythrocyte filterability were influenced by contamination of the test erythrocyte suspensions with leucocytes or plasma proteins or both. We have also been unable to confirm a widely quoted report of reduced erythrocyte ATP concentration in POAD, which was based on a study of four patients and four unmatched controls. ${ }^{17}$ In a separate study ${ }^{28}$ we have shown that POAD erythrocytes have a similar reduction in filterability to that of normal erythrocytes when exposed to an in vitro metabolic stress (low $\mathrm{pH}$, low $\mathrm{pO}_{2}$, and hyperosmolality) designed to simulate the effects of local ischaemia in poorly perfused tissues. The above studies, therefore, suggest that POAD erythrocytes taken from the antecubital fossa do not have a demonstrable loss of deformability within the limits of sensitivity of current techniques.

In rheological studies the patient and control groups should be carefully matched for age, which influences both plasma fibrinogen concentration, ${ }^{29}$ and erythrocyte $\mathrm{MCV} .{ }^{3031}$ Matching for smoking habit is also important since smoking increases fibrinogen concentration, ${ }^{24}$ the $\mathrm{MCV},{ }^{30}{ }^{31}$ and also the leucocyte count. ${ }^{32-34}$ Alcohol intake is a further cause of macrocytosis, ${ }^{3031}$ and since erythrocyte deformability measurements may be influenced by MCV values, both outside the normal range $e^{35}$ and to a much lesser extent within it, the effect of alcohol intake on MCV should be checked in future rheological studies.

We are indebted to the United Birmingham Hospitals Endowment Fund Medical Research Committee and the University of Birmingham Scientific Projects Committee for financial support, to Miss CP Hopwood for ATP measurements, to Technicon International Division for making available an Ektacytometer, and to Mr MH Simms for allowing access to patients attending the vascular clinic.

\section{References}

' Dormandy JA, Hoare E, Colley J, Arrowsmith DE, Dormandy TL. Clinical haemodynamic, rheological, and biochemical findings in 126 patients with intermittent claudication. $\mathrm{Br}$ Med J 1973;iv:576-81.

${ }^{2}$ Dormandy JA, Hoare E, Khattab AH, Arrowsmith DE, Dormandy TL. Prognostic significance of rheological and biochemical findings in patients with intermittent claudication. $\mathrm{Br}$ Med J 1973;iv:581-3.

${ }^{3}$ Kenny MW, Meakin M, Stuart J. Measurement of erythrocyte filterability using washed-erythrocyte and whole-blood methods. Clin Hemorheol 1981;1:135-46.

4 Alderman MJ, Ridge A, Morley AA, Ryall RG, Walsh JA. Effect of total leucocyte count on whole blood filterability in patients with peripheral vascular disease. J Clin Pathol $1981 ; 34: 163-6$.

$s$ Lucas GS, Caldwell NM, Kenny MW, et al. Effect of calciumchelating and non-chelating anticoagulants on erythrocyte and leucocyte filterability. Clin Hemorheol 1983;3:451-67.

- Stuart J, George AJ, Davies AJ, Aukland A, Hurlow RA. Haematological stress syndrome in atherosclerosis. J Clin Pathol 1981;34:464-7. 
' Stuart J. The acute-phase reaction and haematological stress syndrome in vascular disease. Int J Microcirc: Clin Exp 1984;3:115-29.

${ }^{8}$ Reid HL, Dormandy JA, Barnes AJ, Lock PJ, Dormandy TL. Impaired red cell deformability in peripheral vascular disease. Lancet 1976; i:666-8.

' Angelkort B, Maurin N, Boateng K. Influence of pentoxifylline on erythrocyte deformability in peripheral occlusive arterial disease. Curr Med Res Opin 1979;6:255-8.

10 Drummond MM, Lowe GDO, Belch JJF, Barbenel JC, Forbes CD. An assessment of red cell deformability using a simple filtration method. J Clin Pathol 1980;33:373-6.

" Bidet JM, Gilbert M, Cheynel J, Duchene-Marullaz J, Lemarie JC. Red blood cell filterability in non-diabetic patients with chronic occlusive arterial disease. Scand J Clin Lab Invest 1981;41(suppl 156):189-91.

12 Ehrly AM, Köhler H-J. Altered deformability of erythrocytes from patients with chronic occlusive arterial disease. Vasa 1976;5:319-22.

${ }^{13}$ Irwin ST, Rocks MJ, McGuigan JA, Patterson CC, Morris TCM, O' Reilly MJG. Effect of reconstructive vascular surgery on red cell deformability-preliminary results. J Clin Pathol 1983;36:1136-9.

14 Jouve R, Juhan-Vague I, Arnaud C, et al. Erythrocyte deformability and acute phase reactant proteins in arteriosclerosis obliterans patients. Clin Hemorheol 1983;3:481-9.

is Winkenwerder W, Adams K, Lineberger T, Johnson Jr G. Blood filtration in patients with peripheral vascular disease. Clin Hemorheol 1982; 2:201-7.

${ }^{16}$ Stuart J, Kenny MW, Aukland A, et al. Filtration of washed erythrocytes in atherosclerosis and diabetes mellitus. Clin Hemorheol 1983;3:23-30.

${ }^{17}$ Buchanan N, Moodley GP. The effect of pentoxifylline on human erythrocyte adenosine triphosphate. IRCS Med Sci: Cardiovasc Syst 1977;5:43.

${ }^{18}$ Kenny MW, Meakin M, Stuart J. Methods for removal of leucocytes and platelets prior to study of erythrocyte deformability. Clin Hemorheol 1983;3:191-200.

${ }^{19}$ Stuart J, Kenny MW, Meakin M, Lucas GS, Caldwell NM. Leucocyte removal prior to study of erythrocyte deformability. Biorheology 1984;(suppl 1):283-5.

${ }^{20}$ Hanss M. Erythrocyte filtrability measurement by the initial flow rate method. Biorheology 1983;20:199-211.

${ }^{21}$ Lucas GS, Baar S, Caldwell NM, Stuart J. Comparison of silver and polycarbonate membranes for measurement of erythrocyte filterability. Clin Hemorheol 1983;3:513-23.

${ }^{22}$ Stoltz J-F, Duvivier C, Malher E. L'érythromètre: appareil de mesure de la filtrabilité érythrocytaire et de la viscosité plasmatique. In: Viriot M-L, Andre J-C, Lucius M, Stoltz J-F, eds. Techniques Advancées en Hémorhéologie. Nancy: Institut National Polytechnique de Lorraine, 1983:884-9.

${ }^{23}$ Bessis M, Mohandas N. A diffractometric method for the measurement of cellular deformability. Blood Cells 1975;1:307-13.

${ }^{24}$ Mohandas N, Clark MR, Jacobs MS, Shohet SB. Analysis of factors regulating erythrocyte deformability. J Clin Invest 1980;66:563-73

${ }^{25}$ Feo CJ, Nossal M, Jones E, Bessis $\mathbf{M}$. Une nouvelle technique d'étude de la physiologie des globules rouges: la mesure de leur déformabilité en fonction de l'osmolarité. $C \boldsymbol{R}$ Acad Sci Paris 1982;295:687-91.

${ }^{26}$ Inglis TCMcN, Carson PJ, Stuart J. Clinical measurement of whole-blood viscosity at low-shear rates. Clin Hemorheol 1981;1:167-77.

${ }^{27}$ Bücher T. Über ein Phosphatübertragendes Gärungsferment. Biochim Biophys Acta 1947;1:292-314.

${ }^{28}$ Powell JE, Stuart J. Effect of metabolic stress and oxpentifylline on erythrocyte deformability (filterability). Clin Hemorheol (in press).

${ }^{24}$ Meade TW, Chakrabarti R, Haines AP, North WRS, Stirling Y. Characteristics affecting fibrinolytic activity and plasma fibrinogen concentrations. Br Med J 1979;i:153-6.

${ }^{30}$ Chalmers DM, Levi AJ, Chanarin I, North WRS, Meade TW. Mean cell volume in a working population: the effects of age, smoking, alcohol and oral contraception. Br J Haematol 1979;43:631-6.

${ }^{31}$ Papoz L, Warnet J-M, Péquignot G, Eschwege E, Cllaude JR, Schwartz D. Alcohol consumption in a healthy population. Relationship to $\gamma$-glutamyl transferase activity and mean corpuscular volume. JAMA 1981;245:1748-51.

${ }^{32}$ Corre F, Lellouch J, Schwartz D. Smoking and leucocyte counts. Results of an epidemiological survey. Lancet 1971;ii:632-4.

${ }^{33}$ Friedman GD, Siegelaub AB, Seltzer CC, Feldman R, Collen MF. Smoking habits and the leukocyte count. Arch Environ Health 1973;26:137-43.

${ }^{34}$ Helman N, Rubenstein S. The effects of age, sex, and smoking on erythrocytes and leukocytes. Am J Clin Pathol 1975;63:3544.

${ }^{35}$ Kenny MW, Gyde OHB, Stuart J. Influence of cell size on erythrocyte deformability in treated polycythaemia vera. Clin Hemorheol 1984;4:381-6.

Requests for reprints to: Professor J Stuart, Department of Haematology, The Medical School, University of Birmingham, Birmingham B15 2TJ, England. 